\title{
THE CONTRIBUTIONS OF RANGER
}

\section{PHOTOGRAPHS TO UNDERSTANDING THE}

\section{GEOLOGY OF THE MOON}

\section{CONTRIBUTIONS \\ TO \\ ASTROGEOLOGY}

Prepared on behalf of the National Aeronautics and Space Administration

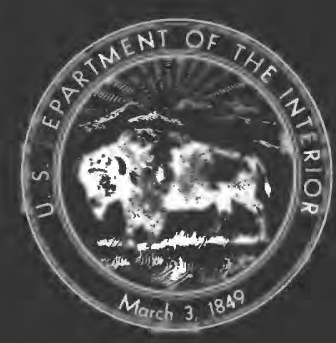

GEOLOGICAL SURVEY PROFESSIONAL PAPER 599-J

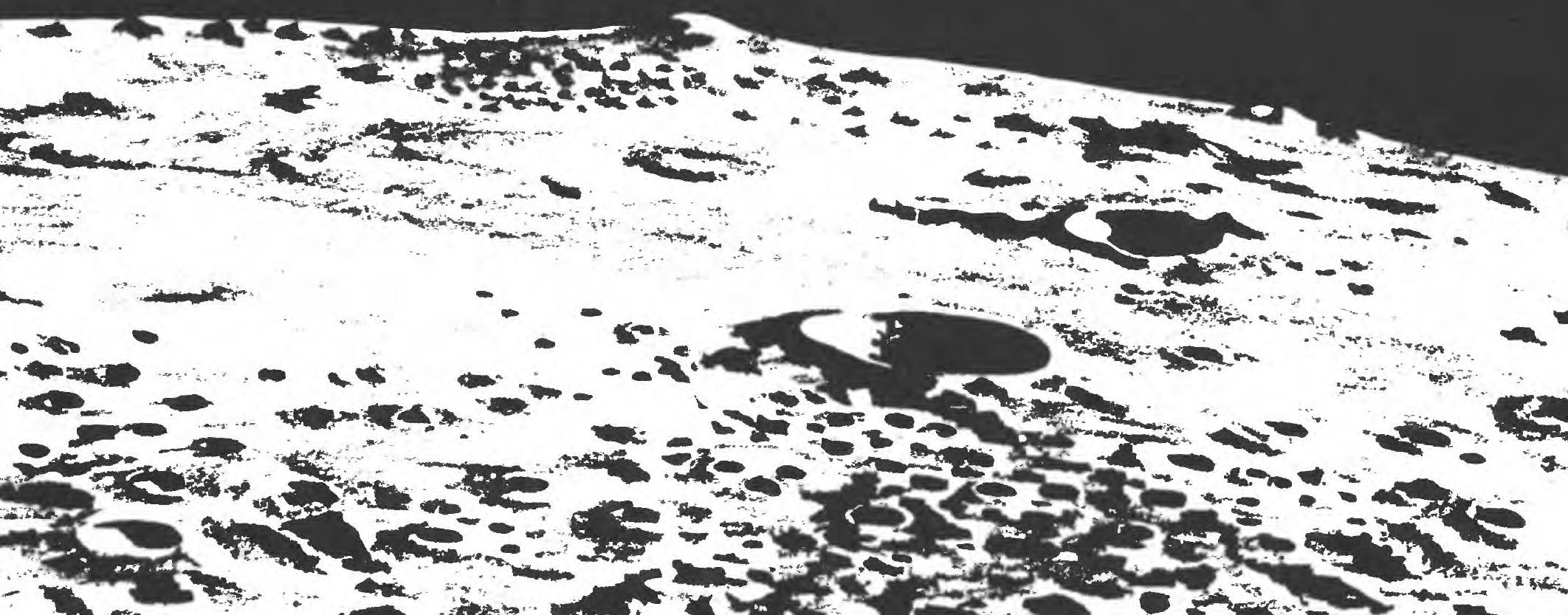




\section{The Contributions of}

Ranger Photographs to

Understanding the

Geology of the Moon

By N. J. TRASK

CONTRIBUTIONS TO ASTROGEOLOGY

GEOLOGICAL SURVEY PROFESIONAL PAPER 599-J

Prepared on behalf of the National Aeronautics

and Space Administration

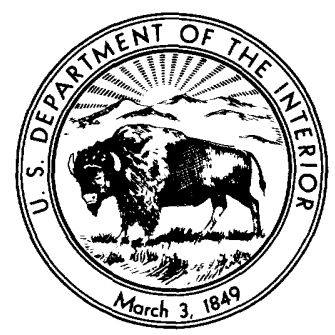

UNITED STATES GOVERNMENT PRINTING OFFICE, WASHINGTON : 19.72 


\section{UNITED STATES DEPARTMENT OF THE INTERIOR \\ ROGERS G. B. MORTON, Secretary \\ GEOLOGIGAL SURVEY \\ V. E. McKelvey, Director}

Library of Congress catalog-card No. 72-600142

For sale by the Superintendent of Documents, U.S. Government Printing Office Washington, D.C. 20402 - Price 40 cents

Stock Number 2401-2111 


\section{CONTENTS}

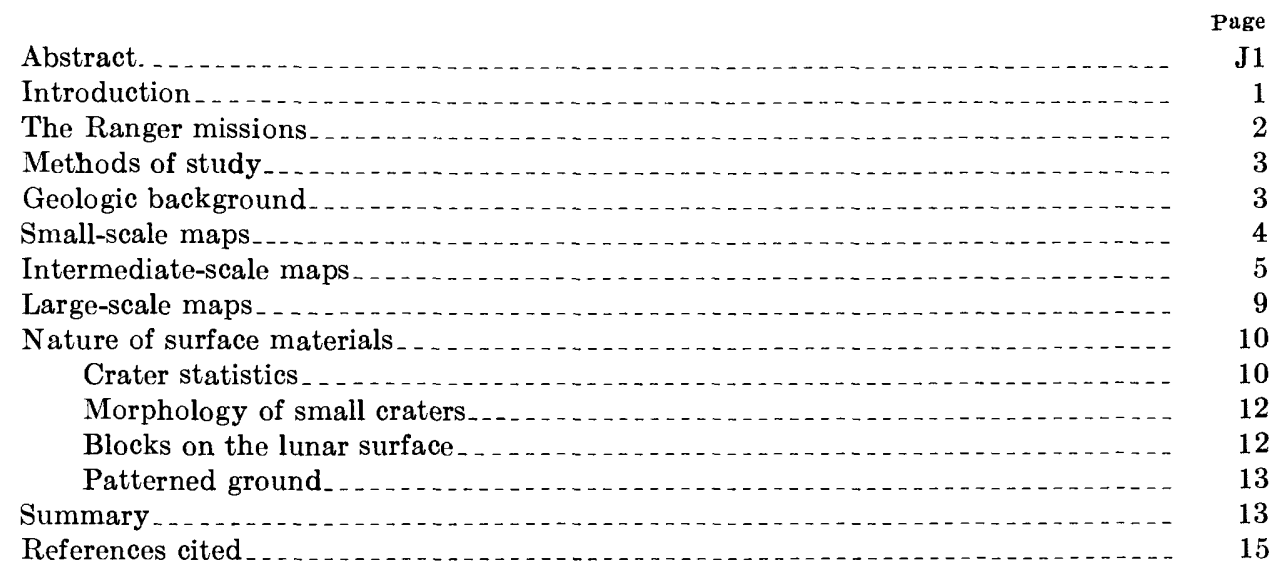

\section{L L U S TR A T I O S}

Frgure 1. Map of the Moon showing impact points of Rangers VIJ, VIrr, and IX

2. Photograph showing mosaic of Ranger IX frames A-66 and B-74, floor of Alphonsus . . . . . . . . . . .

3. Photograph showing Ranger VIr frame A-196, Bonpland H region

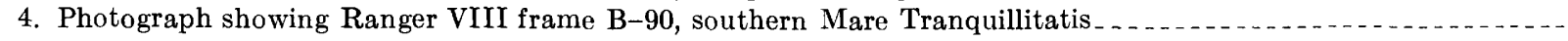

5. Graph showing cumulative size-frequency distributions of craters

6. Diagram showing hierarchy of geologic features in terms of resolution and fractional coverage of planet achieved by a photographic system.

\section{T A B L E S}

TABLE 1. Geologic maps produced entirely or in part from Ranger photographs as part of Ranger geologic mapping project _.

2. Ranger camera characteristics.

3. Lunar stratigraphic and time divisions as shown on $1: 1,000,000$-scale maps $\ldots$

4. Summary of improved geologic knowledge of lunar units as shown on Ranger photographs at increasingly larger scales 



\title{
THE CONTRIBUTIONS OF RANGER PHOTOGRAPHS TO UNDERSTANDING THE GEOLOGY OF THE MOON
}

\author{
By N. J. Trask
}

\begin{abstract}
Vidicon photographs returned to earth by Rangers VII, VIII, and IX in 1964 and 1965 were used to study the details of lunar geologic units previously recognized from earth-based telescopic photographs and to make geologic maps at a variety of scales. The photographs from each mission changed continuously in scale as the spacecraft approached impact. The final frames had resolutions some 1,000 times better than the best earthbased photographs. Lunar stratigraphic units mapped at a scale of $1: 1,000,000$ displayed, at these larger scales, differences in properties and, possibly, in ages, but a clear-cut stratigraphic succession of subunits was not apparent. The plains-forming materials in both terra and mare were divisible into units mainly on the basis of the differences in the total number of superposed craters and in the relative number of craters of various morphologic types. Important details of the rims, walls, and fioors of the craters Sabine and Ritter suggested that these craters might be of internal origin rather than impact origin. A number of smaller craters were interpreted to be of internal origin on the basis of their shape, rim textures, and alinement along linear depressions of structural origin. The largest scale maps showed mainly small craters of various morphologic forms and a few blocks; they served as forerunners of large-scale maps made from Orbiter photographs that were used in planning Apollo missions.

The nature of the uppermost part of the lunar surface was revealed by the statistical abundance and morphology of small craters, the presence of blocks, and the presence of patterned ground. Although not entirely conclusive, these several kinds of evidence, together with lunar photometric and polarimetric data, strongly suggested that the surface consists of fine-grained fragmental material formed, with some local exceptions, by meteorite impact. Subsequent lunar probes have shown that this model is substantially correct.
\end{abstract}

\section{INTRODUCTION}

On July 31, 1964, at 13:25:49 G.m.t. (Greenwich mean time), the Ranger VII spacecraft impacted on the moon after sending to earth some 4,000 television views of the lunar surface. The scenes transmitted just before impact had a resolution 1,000 times better than that of the best earth-based telescopic photographs. Thus was inaugurated the era of closeup geologic investigation of the moon.

Ranger VIII and Ranger IX impacted on the moon on February 20, 1965, and March 24, 1965, and returned to earth some 7,000 and 6,000 photographs, respectively. The quality of many of the photographs taken early in all three missions is inferior to that of earth-based telescopic photographs, but it improves dramatically, as does resolution, in photographs taken as each spacecraft neared the lunar surface. Each suite of photographs, therefore, provides a bridge between the appearance of the lunar surface at telescopic resolutions (approximately $1 \mathrm{~km}$ ) and its appearance at resolutions down to about $1 \mathrm{~m}$ (meter). Prior to the successful Ranger missions, earth-based telescopic photographs and observations had been used by the U.S. Geological Survey to make reconnaissance geologic maps of the moon at a scale of $1: 1,000,000$. The moonwide geologic picture provided by this mapping helped in targeting the Rangers and in placing the Ranger photographs in context. The Ranger photographs in turn provided closeup views of several of the units that had been mapped at small scale and suggested a program of more detailed geologic mapping of the small areas covered by the three missions. This report summarizes the results of that mapping program.

A total of seven maps at scales ranging from 1:250,000 to $1: 5,000$ were prepared; in addition, the Ranger data were used to revise and clarify geologic relations on published versions of two quadrangles in the $1: 1,000,000$ series (table 1 ). This report is intended to be used in conjunction with these maps and to summarize the contributions of the Ranger program to understanding the geology of the moon. At the time the Ranger program began, it had the additional purpose of exploring various methods and procedures that might be used in large-scale geologic mapping from photographs with a much wider format to be provided 
by the Lunar Orbiters. Although Ranger photographs of some areas were not as useful as the later Orbiter photographs, they were important to the lunar program at a time when this conceptual foundation was being developed.

The main previous analyses and interpretations of the Ranger photographs were published by JPL (Jet Propulsion Laboratory, California Inst. of Technology, Pasadena, Calif.) (Heacock and others, 1965, 1966), and in a general volume on the lunar surface, which appeared shortly after the missions (Hess and others, 1966). Emphasis in these early reports was on considerations of the origins of the several types of features shown on the photographs; several of the reports placed considerable emphasis on terrestrial analogs. The report on the Ranger VIII and IX photographs (Heacock and others, 1966) included five preliminary geologic maps of selected areas by M. H. Carr, D. J. Milton and D. E. Wilhelms, J. F. McCauley, N. J. Trask, and H. H. Schmitt. These maps provided the starting point for the program of Ranger geologic mapping.

TABLE 1.-Geologic maps produced entirely or in part from Ranger photographs as part of Ranger geologic mapping project

\begin{tabular}{|c|c|c|c|}
\hline Mission & Small scale & Intermediate scale & Large scale \\
\hline Ranger VII.- & & $\begin{array}{l}\text { Bonpland H region } \\
\text { (U.S. Geol. Survey, } \\
\text { 1971). }\end{array}$ & $\begin{array}{l}\text { Bonpland PQC } \\
\text { region (Titley, } \\
\text { 1971). }\end{array}$ \\
\hline Ranger VIII.- & $\begin{array}{l}\text { Theophilus quad- } \\
\text { rangle (Milton, } \\
\text { 1968); }{ }^{2} \text { Sabine } \\
\text { region (Wilshire, } \\
\text { 1967). }\end{array}$ & $\begin{array}{l}\text { Sabine DM region } \\
\text { (Trask, 1969). }\end{array}$ & $\begin{array}{l}\text { Sabine EB region } \\
\text { (Cannon and } \\
\text { Rowan, 1971). }\end{array}$ \\
\hline Ranger IX - & $\begin{array}{l}\text { Ptolemaeus quad- } \\
\text { rangle (Howard } \\
\text { and Masursky, } \\
\text { 1968); }{ }^{2} \text { Alphonsus } \\
\text { region (Carr, 1969). }\end{array}$ & $\begin{array}{l}\text { Alphonsus GA region } \\
\text { (McCauley, 1969). }\end{array}$ & \\
\hline
\end{tabular}

1 Also mapped in preliminary form (Titley, 1968).

2 Part of 1:1,000,000 series, which covers most of the earthside hemisphere.

The program was carried out on behalf of NASA, the National Aeronautics and Space Administration, under contract WO-5171 over the period from September 1965 to June 1968. JPL provided the photographs as well as much helpful information and assistance. The authors of individual maps in the Ranger series are cited in the body of this report. The program was coordinated during its first year by John F. McCauley and later by the author.

\section{THE RANGER MISSIONS}

Six vidicon cameras, whose characteristics are described in table 2, made up the scientific package on each of the Ranger missions. These cameras record images in the following manner: A layer of charged photoconductive material is exposed to the scene by means of an electromagnetically driven shutter. Variations in the brightmess of the scene cause variations in the resistance across the photoconductive surface. An electron beam then scans the surface and recharges the photoconductor. The variation in charge current obtained during the scanning is the video signal. This signal, consisting of amplitude variations, is amplified, converted to frequency variations, and transmitted to earth. The television signals from the Ranger spacecraft were received at the Goldstone facility in California, converted back to amplitude variations, and displayed on a cathode ray tube. The reconstructed image on the cathode ray tube was then photographed on $35-\mathrm{mm}$ film. In addition to the film records, a magnetic tape recording was made of the frequency-modulated signal.

In assessing the use of the Ranger photography for geologic and topographic purposes, it is important to keep in mind the major differences between this process and that used to obtain conventional aerial photography.

TABLE 2.-Ranger camera characteristics

\begin{tabular}{|c|c|c|c|c|c|c|}
\hline \multirow{2}{*}{ Characteristic } & \multicolumn{6}{|c|}{ Camera } \\
\hline & $\mathbf{A}$ & B & $P_{1}$ & $\mathrm{P}_{2}$ & $\mathrm{P}_{3}$ & $\mathrm{P}_{4}$ \\
\hline $\begin{array}{l}\text { Focal length (mm) } \\
\text { f number } \\
\text { Frame time }(\mathrm{sec}) \\
\text { Exposure time }(\mathrm{msec}) \\
\text { Field of view (deg) } \\
\text { Target size (mm) } \\
\text { Scan lines.... } \\
\text { Time between frames (sec) }\end{array}$ & $\begin{array}{c}25 \\
1.0 \\
2.56 \\
5 \\
25 \\
11 \\
1,150 \\
5.12\end{array}$ & $\begin{array}{c}76 \\
2.0 \\
2.56 \\
5 \\
8.4 \\
11 \\
1,150 \\
5.12\end{array}$ & $\begin{array}{l}76 \\
2.0 \\
.2 \\
2 \\
2.1 \\
2.8 \\
300 \\
\quad .84\end{array}$ & $\begin{array}{l}76 \\
2.0 \\
.2 \\
2 \\
2.1 \\
2.8 \\
300 \\
\quad .84\end{array}$ & $\begin{array}{l}25 \\
1.0 \\
.2 \\
2 \\
6.3 \\
2.8 \\
300.84\end{array}$ & $\begin{array}{c}25 \\
1.0 \\
2.2 \\
6.3 \\
2.8 \\
300 \\
.84\end{array}$ \\
\hline
\end{tabular}

1 The actual field of view is somewhat smaller than the given numbers because of the presence of a mask at the edge of the vidicon target which is used to determine scene black on each scan of the electron beam.

The fields of view of the six cameras partially overlapped so that some parts of the lunar surface appeared in the images of two or more cameras-an essential safety characteristic of early space photography experiments. Two cameras had a full format (11 by $11 \mathrm{~mm}$ ), four a reduced format $(2.8$ by $2.8 \mathrm{~mm})$. These sizes should also be kept in mind when comparing enlargements ( 9 by 9 in., for example) of the Ranger records with conventional aerial photographs. The short focal length cameras had a system angular resolution of $8.8 \times 10^{-4}$ radians, and the long focal length cameras a system angular resolution of $2.9 \times 10^{-4}$ radians. In comparison, the Lunar Orbiter film system had a system angular resolution of $2.1 \times 10^{-5}$ radians for the long focal length camera. Although a Lunar Orbiter type system would have given much better resolution than that provided by Ranger, such a system requires the onboard development of film and thus would clearly have been impractical for an impacting mission, wherein all the images are returned to earth in a short time.

The aiming points for the three Ranger missions were chosen with a view to learning about the nature of the lunar surface as a whole and to providing information needed for the Surveyor and Apollo programs of lunar landings. Rangers VII and VIII impacted on mare 
material near the lunar equator, Ranger IX on the floor of the highland crater Alphonsus (fig. 1). It was known before the Ranger missions that the first manned lunar landings would probably be on mare material; hence the first two Rangers were sent to investigate the maria. Ranger VII was aimed at an area referred to at the time as an embayment or sinus at the north end of Mare Nubium; after the Ranger VII mission this area was renamed Mare Cognitum ("the sea that is known"). It has a slightly reddish hue (Kuiper, 1965) and is crossed by several rays of the systems surrounding both Tycho and Copernicus. The impact point was on a faint ray. Ranger VIII was aimed at the southwest corner of Mare Tranquillitatis, an area that reflects more strongly in the bIue part of the spectrum than the Ranger VII area and is unrayed within $5 \mathrm{~km}$ of the impact point. As it cruised toward impact, Ranger VIII photographed large areas of the uplands southwest of Mare Tranquillitatis and the two craters Sabine and Ritter at better than earth-based resolution. The areas near the impact points of Rangers VII and VIII were not greatly different in their large-scale appearance, and a highland site was clearly indicated for Ranger IX. The crater Alphonsus was chosen because of the small dark-halo craters on its floor and because reports of transient lunar phenomena within the crater (Kozyrev, 1962) had gen-

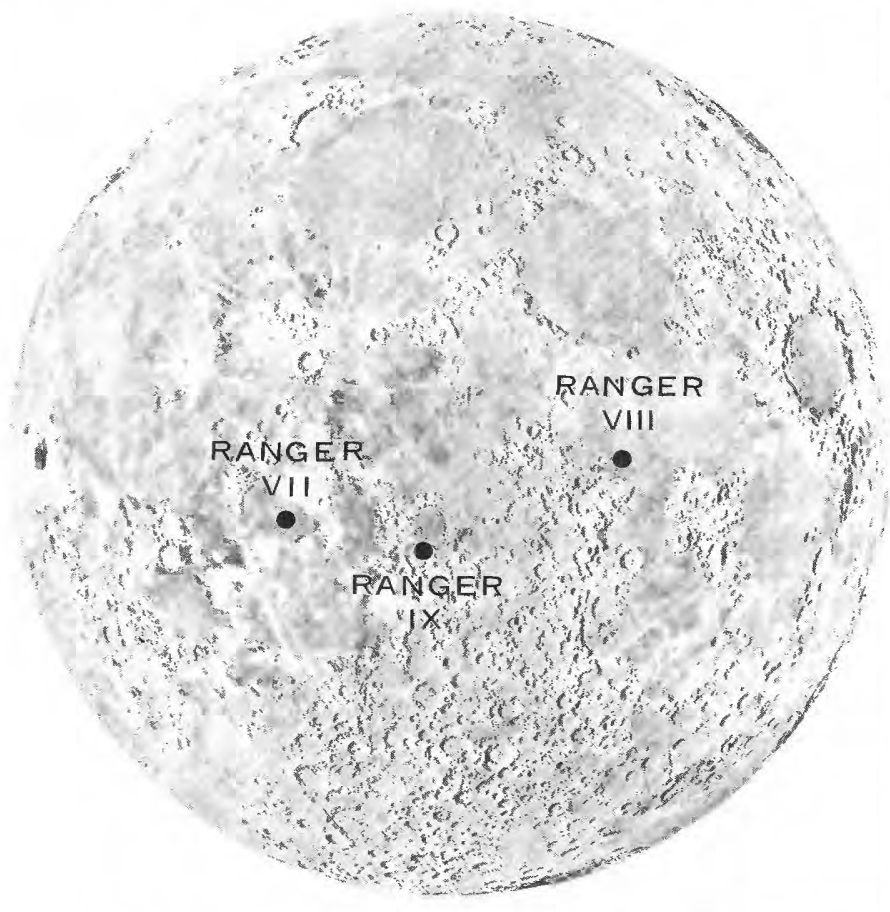

FIGURE 1.-Impact points of Ranger VII, VIII, and IX. erated considerable interest in its detailed appearance. The level, highly cratered plains-forming material on the floor is similar to many other tracts on the lunar highlands. Before it impacted, Ranger IX provided views at better than earth-based resolution of the rugged highlands, smooth terra plains, and maria surrounding Alphonsus.

\section{METHODS OF STUDY}

Stereoscopic and monoscopic examination of goodquality sets of the Ranger photographs ${ }^{1}$ has been the principal method of study used to construct the maps. The base-height ratio in pairs of the photographs is very weak for good stereopsis; nevertheless, stereoscopic viewing is extremely helpful in emphasizing subthe detail and suppressing the lines and spots produced by noise in the transmission system. The geologic interpretation was checked against available Lunar Orbiter photographs of the areas under consideration. The geologic data were plotted on shaded-relief base maps prepared by the U.S. Air Force Aeronautical Chart and Information Center.

Information on the albedo of the lunar surface in the areas covered by some of the small- and intermediatescale maps was obtained from earth-based telescopic photographs taken near full moon; for several maps, the albedo information was systematized by scanning the full-moon photographs with a microphotometer and tracing out lines of equal photographic intensity with an isodensity tracer.

\section{GEOLOGIC BACKGROUND}

Geologic maps at a scale of $1: 1,000,000$ prepared from earth-based observations provide the background against which to consider the new information that the Ranger photographs conveyed. (For reviews see Wilhelms, 1970, and Mutch, 1970.) A lunar stratigraphic column has been worked out for the region around Mare Imbrium, where a series of well-defined map units is visible (Shoemaker and Hackman, 1962). Some of these units can be correlated with similar-appearing units in other parts of the moon. The major time-stratigraphic divisions (systems) correspond to periods of time marked by major events in the Mare Imbrium region (table 3).

\footnotetext{
${ }_{1}^{1}$ Highest quality prints are available in a limited number of photographic editions prepared by G. P. Kulper for the Jet Propulsion Laboratory. Collections of half-tone prints were assembled by National Aeronautics and Space Administration (1964, 1965a, b, 1966a, b).
} 
TABLE 3.-Lunar stratigraphic and time divisions as shown on 1:1,000,000-scale maps

[Materials interpreted as predating the formation of the Imbrium basin (other mare basin matertals and crater materials) are designated preImbrian and are not assigned to systems. From top to bottom, most recent to oldest]

Period (system)

Copernican

Formation of large ray craters (such as Copernicus).

Eratosthenian

Formation of large craters whose rays are no longer visible (such as Eratosthenes).

Imbrian

Deposition of most of the mare materials; formation of premare craters (such as Archimedes) ; formation of the Imbrium basin.

Determination of the relative ages of lunar geologic units and the development of the stratigraphic column outlined depend on the principles of superposition and intersection, used for many years in terrestrial geology. Units which fill craters are younger than the craters; units cut by faults are older than the faults, and so forth. Some of the units shown on 1:1,000,000-scale reconnaissance maps probably formed by a single process within a very limited time span. Examples are the ejecta blankets around large craters and around mare basins. Other units, such as the plains-forming materials that make up the maria and parts of the highlands, are more likely to have been built up by a succession of discrete subunits over a lengthy span of geologic time. It was hoped that the Ranger photographs would permit the delineation of these discrete subunits in the same way that lowaltitude photographs of a volcanic field permit the mapping of individual flows not distinguishable on lower resolution views.

A number of subunits were mapped on the plainsforming materials, as described later; however, the distinctions between these subunits were based mainly on differences in crater density and the relative proportions of various crater types. The origin of the subunits was not clear, and a clear-cut stratigraphic succession was not apparent. In this respect, the high-resolution Ranger photographs were something of a disappointment. It is now known that the reason why the plainsforming materials appear so similar on all highresolution photographs and why well-defined stratigraphic units are not evident, is that almost everywhere on the moon there is a soillike debris layer, or regolith, at least several meters thick which, viewed closeup, tends to mask the differences between units that are relatively thin or of limited extent.

In the following summary, the discussion will focus first on small-scale maps $(1: 1,000,000$ and $1: 250,000)$ and the contribution of the Ranger data to some of the broad problems of lunar stratigraphy encountered in the reconnaissance mapping. Most of the units on the small-scale maps can be reasonably assigned to parts of the lunar stratigraphic column outlined in table 3. Intermediate-scale maps $(1: 100,000-1: 50,000)$ and largescale maps $(1: 10,000-1: 5,000)$ are then discussed. Because of the small areas covered by these maps and the presence of the lunar regolith, units cannot be assigned to the stratigraphic column (table 3) with any certainty.

The last section of the report summarizes the collective evidence from all three missions pertaining to moonwide surficial processes involved in the development of this regolith.

\section{SMALL-SCALE MAPS}

Two 1:1,000,000-scale maps, prepared largely from telescopic data, were augmented by Ranger VIII and Ranger IX data; two additional 1:250,000-scale maps were prepared from the photographs of these missions (table 1). Full-format Ranger photographs pertinent to mapping at these scales have fields of view on one side ranging from 75 to $250 \mathrm{~km}$ and resolutions, on the lunar surface, ranging from 500 to $200 \mathrm{~m}$. Mare materials appear essentially uniform at these scales, but terra materials and crater materials display variations that enable subunits to be distinguished. These terra subunits are shown in greatest detail on the Ranger IX photographs; thus in proceeding from small- to large-scale investigations, it is most convenient to start with the Ranger IX data.

Telescopic investigations had shown that plains-forming materials similar to the lunar maria, but with higher albedo, occurred in many patches over the entire terra. Around the periphery of the Imbrium basin, these materials were mapped as the Cayley Formation (Morris and Wilhelms, 1967). Ranger IX photographs of the crater Alphonsus and its environs showed that the formation not only covers the floor of the crater but also fills very small local depressions high in the surrounding mountains; also, the photographs enabled Howard and Masursky (1968) to map the distribution of this unit more accurately than had been possible with telescopic data only.

The Cayley Formation mapped on the floor of Alphonsus by Howard and Masursky in the Ptolemaeus quadrangle (scale 1:1,000,000) can be divided into two distinct units, one highly cratered and the other less cratered, at a map scale of $1: 250,000$ (Carr, 1969):

The cratered unit is almost completely 'saturated with craters, especially those that range from 300 meters to $3 \mathrm{~km}$ in diameter, whereas the crater density of the smooth unit is comparable to that of typical mare material. Most of the craters [on both units] are shallow with rounded subdued rims and, in contrast to many craters in mare areas (outside map area) blocks are almost completely absent. Several low positive relief features, 
principally northwest- and northeast-trending ridges, occur on the floor, especially in the west half.

The Cayley Formation is now thought to be a mixture of volcanic materials and erosional debris derived from the highlands which in most places surround it. Howard and Masursky (1968) believed that much of the unit can be attributed to highly fluid flows, perhaps ash flows, which were widely deposited, shed off highs, and ponded in basins. The two discrete units within the formation on the floor of Alphonsus suggest successive pulses in the development of the Cayley consistent with volcanism playing some role in its genesis.

Other features on the floor of Alphonsus which could be portrayed with increased clarity on small-scale maps were the dark-halo craters and craters on rilles (fig. 2). The dark-halo craters have unusually low albedos for small craters on the terra; the dark material covers not only the outer rims but the interiors of the craters as well. The Ranger photographs show clearly that the dark material fills parts of the rilles along which the craters are located. In these respects these dark-halo craters differ from many other dark-halo craters on the moon which have interiors of moderate to high albedo and which have no obvious structural control. Other craters on the floor of Alphonsus are located along rilles, but their albedo is the same as that of the surrounding materials.

The origin of the crater Alphonsus is not clear; most likely it is an ancient impact scar. Clearly, it has been severely modified by volcanism since its formation, as argued by Carr (1969) :

The dark-halo craters provide the clearest evidence of volcanism within Alphonsus. The fact that they are located on rilles is clearcut evidence of structural control. Furthermore, because their rim materials fill adjacent depressions, they are not subsidence features. The similar rille craters $* * *$ are probably older dark-halo craters whose halos have been destroyed by overturn of the near-surface materials. Other probable volcanic craters are those which form chains *** parallel to structural lineaments on the floor and rim of Alphonsus. The volcanism was possibly triggered by the Alphonsus impact (Carr, 1964), which may have created a local thermal anomaly and caused extensive brecciation beneath the crater, enabling magma to rise to the surface.

The area photographed by Ranger VIII near Delambre southwest of the impact point contains both plains-forming materials and more rugged terrain. On the geologic map of the Theophilus zuadrangle (scale 1: 1,000,000), Milton (1968) distinguished two units-a rugged unit and a relatively smooth unit with scattered domes and irregular depressions. Two basic units, a hilly unit and a plains unit, were also recognized in the same area on the Ranger VIII photographs. These were further divided by Wilshire (1967) on the geologic map of the Sabine region (scale 1:250,000). The plains- forming materials were divided into three subunits according to the number of small craters superposed on each unit. These subunits are probably analogous to the subunits in the Cayley Formation on the floor of Alphonsus. The hilly unit was divided by Wilshire according to the ruggedness of the topography; the units range from gently undulating to rugged steep hills.

The two large craters Ritter and Sabine, in the southwest corner of Mare Tranquillitatis, posed a problem for lunar geologists in pre-Ranger studies. The fact that these two very similar craters are so close together but that neither appears to have deformed the other led some workers to suspect that they might be of internal origin-calderas which formed by collapse of a pile of volcanic deposits. Whether the craters were older or younger than the mare was also in doubt. These relationships were greatly clarified by the Ranger VIII photographs. Wilshire (1967) interpreted both craters as of internal origin,

*** because the percentage of their floors that is occupied by slump blocks is greater than in impact craters of comparable size and because a field of secondary impact craters such as is found around typical post-mare impact craters of comparable size appears to be lacking. Ritter and Sabine are clearly younger than the formation of the mare material because the hummocky ejecta blanket surrounding them partly buries the two major graben structures (Rimae Hypatia I and II) that in turn cut the mare material.

Also, the floors of the craters are anomalously high for postmare craters, and the rim materials are gently rolling and relatively smooth, unlike the rough, hummocky deposits that surround probable postmare impact craters such as Copernicus. Sabine and Ritter thus appear to be more like terrestrial calderas than impact structures; they are similar to the crater Kopff within the inner ring of the Orientale basin, which McCauley (1968) suggested might be of internal origin on the basis of evidence in Lunar Orbiter IV photographs.

\section{INTERMEDIATE-SCALE MAPS}

Map scales ranging from 1:100,000 to $1: 50,000$ are classed here as intermediate. Three maps were made at these scales, one from each mission (table 1). The fullformat Ranger photographs used have fields of view on one side ranging from 5 to $75 \mathrm{~km}$ and resolutions ranging from 200 to $10 \mathrm{~m}$. All level areas on the moon appear more intensely cratered on these photographs (figs. 2, 3,4) than on photographs of smaller scale. On both intermediate- and large-scale maps, units associated with craters occupy a significant fraction of the mapped area.

The system used to map the craters was entirely descriptive. Materials of craters with sharp rims and bright halos formed one map unit, those of slightly sub- 
CONTRIBUTIONS TO ASTROGEOLOGY

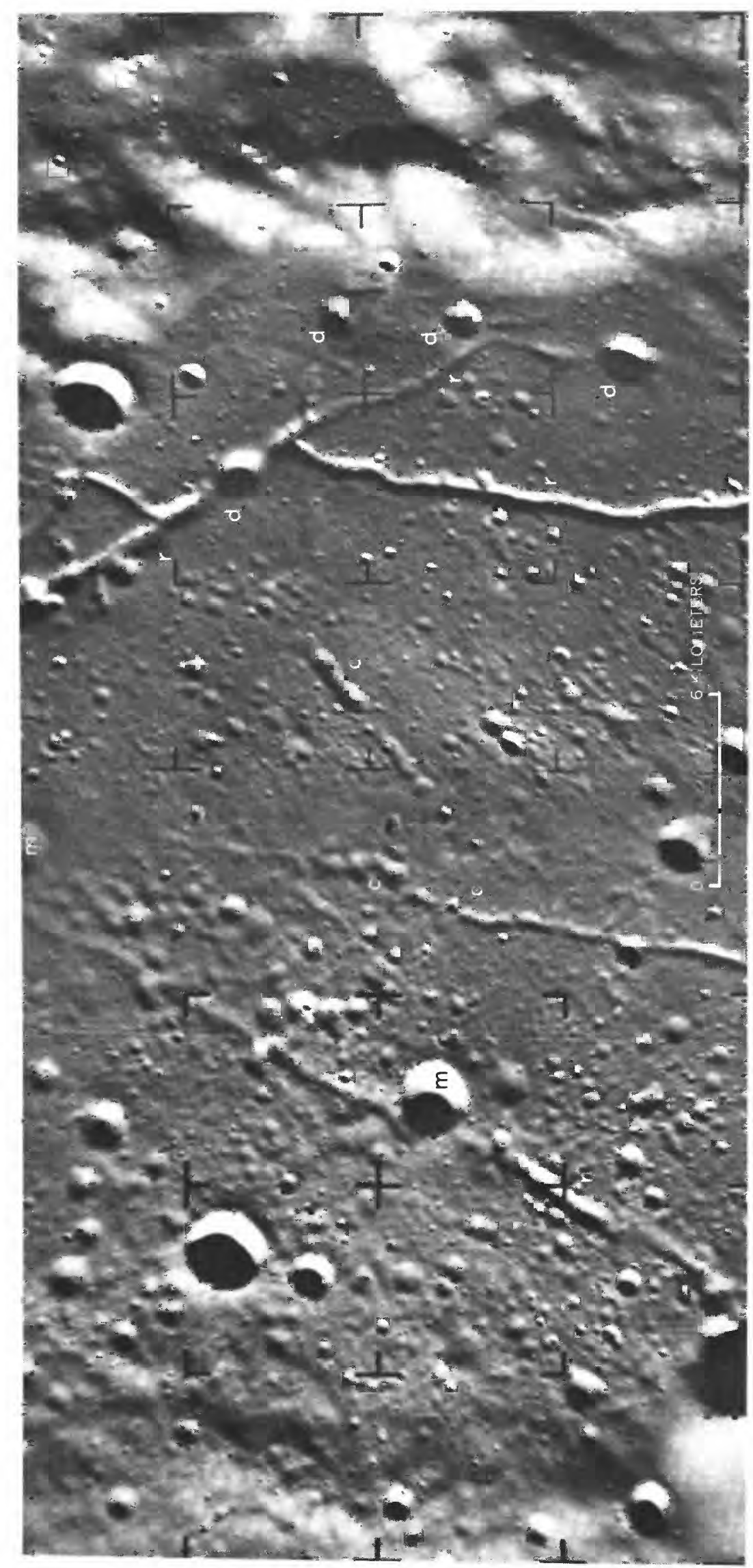

.5

密

密岁

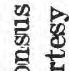

运

दे

눙

峞

욤

영

整客

苞

늉

尊客

की

药

क्य

क

웡

क्षे

E.

홍

율

혼

논

है

हैं

을

药

I

氖

8

(3)

岁

赵

일

㝴苛

…

해을

हึ

떵 오

荡

驾

i

$\ddot{v}$

鼠

总 
dued craters with albedos the same as the surrounding material formed another, and so on. Any other system would have involved assumptions about the origin of the craters; as noted in the final section of this report, the Ranger photographs alone did not permit firm conclusions on this question. Mapping based on Lunar Orbiter photographs, in contrast, was based on the assumption that the subdued craters and gentle depressions had once been sharp and had been degraded by subsequent impacts and downslope movement of material-an assumption that seemed reasonable after examining the entire body of Lunar Orbiter photographs. Craters were then mapped according to their relative ages. Small highly subdued craters were inferred to be the same age as larger sharper craters because crater destruction proceeds faster for small craters than for larger craters. On maps made from Orbiter photographs, therefore, a map unit shows craters of the same inferred age, even though they may have different morphologies.

The large number of craters made it difficult to map stratigraphic units on intermediate-scale maps. Some additional subdivisions of the Cayley Formation were mapped, however, and some fairly distinct subdivisions of the mare material were recognized. The two subunits of the Cayley Formation on the floor of Alphonsus, recognized at small scales, were mapped by McCauley (1969) at a scale of $1: 50,000$. In addition, he recognized two units in the heavily cratered part of the formationone with a northeast lineation trend and one with both a northeast and northwest lineation trend. The differences in the crater populations on these units, as well as on others, within the crater Alphonsus were documented by McCauley (1969) with detailed crater statistics. The total number of craters on each stratigraphic unit was presented; in addition, all craters larger than approximately $200 \mathrm{~m}$ were classified according to morphologic freshness, and counts were made of each morphologic type on each unit.

The Cayley Formation on the floor of Alphonsus can be seen at this scale to have a large number of craters with low, smooth gently convex upward rims. These craters are "morphologically distinct, and the majority of those mapped show evidence of structural control. These are interpreted as volcanic craters of the maar type which played an important role in filling the Alphonsus basin" (McCauley, 1969). (See fig. 2, this report.) The floor of Alphonsus also has numerous northand northeast-trending rilles and linear depressions (fig. 2), some with steep walls, flat floors, and sharp edges and others with shallower, U-shaped floors and rounded edges. One rille passes gradationally into a series of coalescing low-rimmed craters of the type in- terpreted as maars. The rilles and "linear depressions may be eroded and partly filled remnants of originally sharper fault troughs such as Rima Alphonsus I. Some, however, particularly those that grade into rimless chain craters, are probably collapse structures" (McCauley, 1969).

Features of internal origin such as convex-rimmed craters and linear depressions and troughs and associated craters appear to be especially numerous on the floors of craters. The floor of Copernicus has many such features, as well as possible cinder cones (Hartmann, 1968). The craters and depressions of internal origin on the floor of Alphonsus may be the worndown equivalents of features that once resembled those now seen on the floor of Copernicus. In this respect, the Cayley Formation on the floor of Alphonsus may differ from the formation where typically developed outside of craters such as in its type area (Morris and Wilhelms, 1967). Lunar Orbiter photographs (site II P-4, for example) indicate that features that are clearly of internal origin are rare in these areas outside of large craters, and the smooth less-cratered subunit which covers much of the floor of Alphonsus is less widespread.

Divisions within the mare material were mapped by Trask (1969) on the basis of Ranger VIII photographs in the Sabine DM region, a part of southwest Mare Tranquillitatis (scale 1:50,000). Mare material makes up one of the most widespread continuous geologic units on the moon, is confined largely to the earthside hemisphere, and is the site of the first two Apollo landings. Understanding of possible local, large-scale variations in these materials was an early goal of lunar geologic research. The nomenclature of the mare materials has undergone continual revision. (For a review, see Wilhelms, 1970.) On current small-scale maps, the materials are referred to simply as mare material; most of this unit is assigned to the Imbrian System (table 3 ), but some fairly large patches have been assigned to the Eratosthenian. The mare material in the Sabine DM region can be seen on Orbiter photographs to be properly assigned to the Imbrian System; the limited coverage of the Ranger photographs did not permit such an assignment, and the material was mapped only as mare material, age unassigned.

The two divisions mapped in the mare material are "(1) [a] unit *** with a relatively high density of subdued craters in the size range $50-200$ meters, and (2) a smoother unit *** with a lower areal density of such craters and fewer indistinct ridges and irregular depressions" (Trask, 1969). The smoother, less-cratered, unit appears to lie slightly below the more-heavilycratered unit, although this appearance may be only an illusion because the photographs have very weak stereopsis. Trask (1969) interpreted the smooth unit as 
a relatively thick accumulation of impact-produced debris, and the more-cratered unit as an area where such debris is relatively thin. Similar, relatively smooth units in other areas have been interpreted as volcanic materials younger than the more-heavily-cratered terrain.

The Bonpland $\mathrm{H}$ region, photographed by Ranger VII and mapped at 1:100,000 (U.S. Geol. Survey, 1971), is characterized by distinct clusters of craters, including both circular craters and elongate gouges and depressions (fig. 3). These are apparently fields of secondary impact craters; however, not all can be clearly associated with a given primary. All the clusters in the central part of the region were attributed to the crater
Tycho by Shoemaker (1966) ; Kuiper (1965), however, attributed some clusters to Tycho and some to Copernicus. A careful analysis of the albedo patterns around the clusters, as well as of the morphology and distributions of craters within each cluster, suggested that the secondary impact craters were indeed related to both Tycho and Copernicus (U.S. Geol. Survey, 1971).

Mare ridges are also conspicuous in the Bonpland $\mathrm{H}$ region. Their intricate complexity was shown for the first time by the Ranger VII photographs. The positive topography of the ridges extends up onto the rims and to the rim crests of several fairly young craters, and one ridge appears to cross a crater floor. These observations

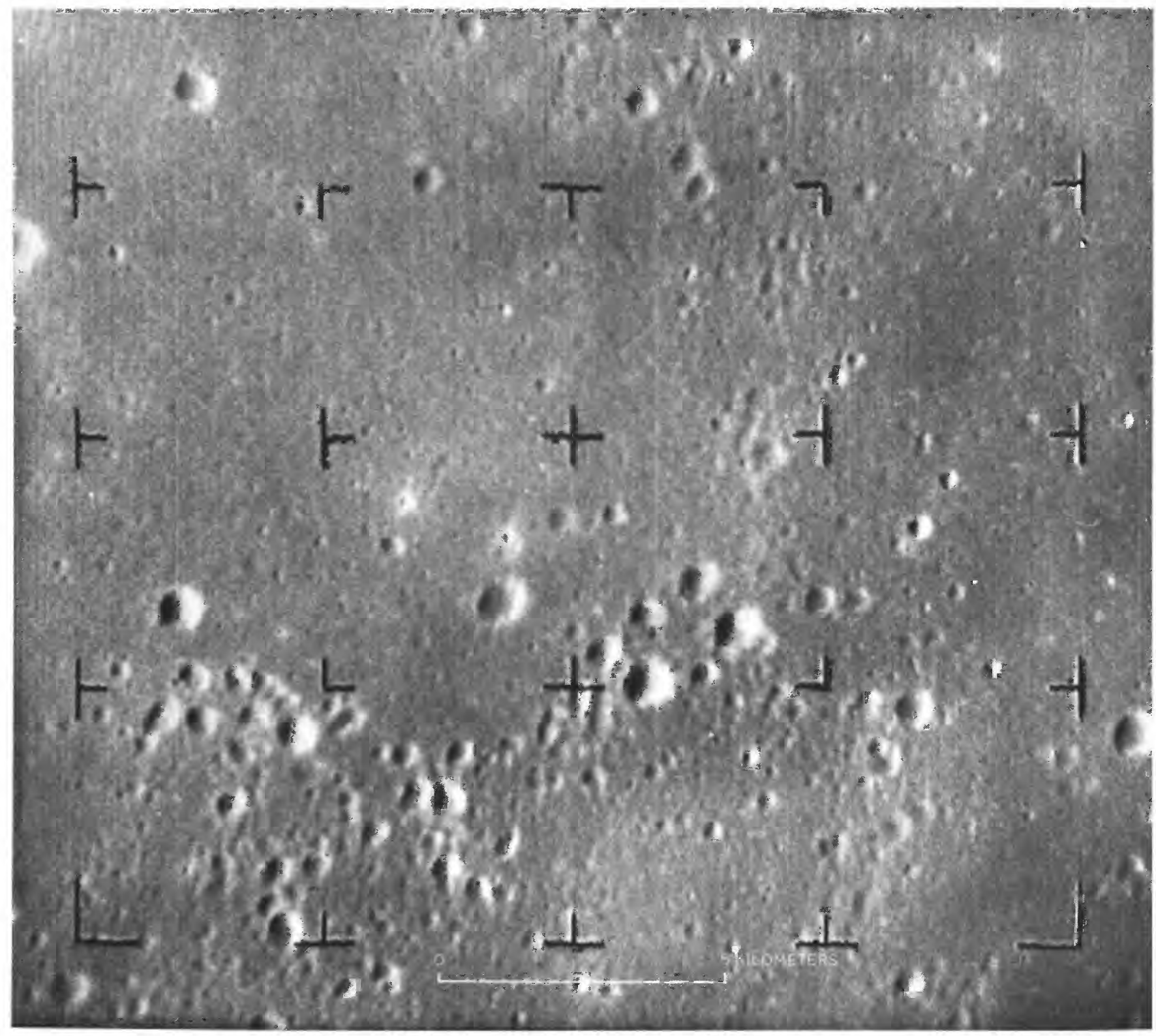

Figure 3- Ranger VII A-camera frame 196 taken 18 seconds before impact showing clusters of circular craters and elongate gouges and depressions in Bonpland $\mathrm{H}$ region. North at top. 
led Urey $(1965$, p. 143) to suggest that the ridges are younger than the craters. The relationship, however, may actually be the opposite of this (U.S. Geol. Survey, 1971); specifically, the rim deposits of the craters may have slumped off the topographic highs of the ridges, or they may have been initially thinner there and thus unrecognizable on the photographs. The ridge crossing the crater floor could be a resistant dike that predated the crater and is now expressed by positive relief.

\section{LARGE-SCALE MAPS}

Two large-scale maps were prepared, both in mare areas - one at $1: 10,000$ in the Ranger VII impact area (Titley, 1971) and one at 1:5,000 near the Ranger
VIII impact point (Cannon and Rowan, 1971). The field of view of full-format photographs used ranged from 1 to $5 \mathrm{~km}$ on one side, and the resolutions from 1 to $10 \mathrm{~m}$. The final partial-format photographs with fields of view as small as $60 \mathrm{~m}$ on one side were also used. At these scales, the lunar surface everywhere is covered with innumerable craters ranging downward in size to the limit of photographic resolution. Positiverelief features are rare, but blocks appear here and there (fig. 4; Kuiper, 1966), hinting at but not demonstrating the particulate nature of the surface materials. Because of the large number of small craters and the cover of particulate material, the large-scale photographs do not reveal any stratigraphy in the underlying bedrock, but

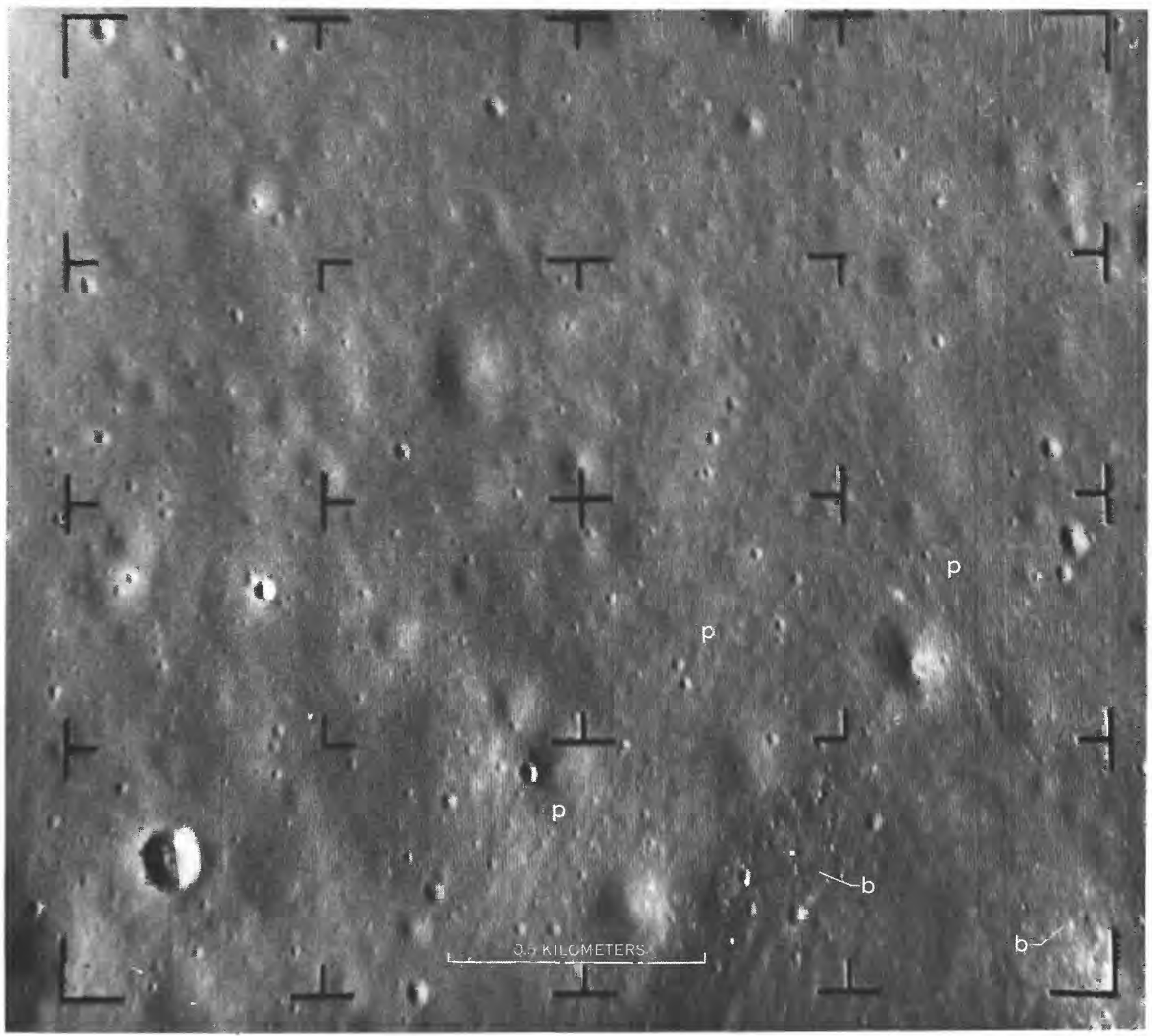

Figure 4.-Final Ranger VIII B-camera frame 90 taken just before impact in southern Mare Tranquillitatis, showing numerous small sharp craters superposed on larger more subdued craters: p, patterned ground on rim of large pan-shaped depression; b, field of blocks up to $10 \mathrm{~m}$ across. North at top. 
record only variations from place to place in surface topography. They were thus valuable for determining the fine-scale nature of the surface material and for assessing properties critical to the problem of landing on the lunar surface at a time when nothing else was known about the moon at these scales. The inferences that were made about the surface materials are summarized in the section "Nature of Surface Materials."

Maps made from these large-scale photographs yield practical information, rather than new stratigraphic insights, and are similar to maps that were later produced from Orbiter photographs and used to guide the course of Apollo missions on the surface and to place the results of such exploration in proper context. They are roughly analogous to detailed, large-scale mine maps that guide a prospector in searching for new ore. Individual craters and blocks were the principal elements mapped. The craters range from sharp, bright-haloed distinct craters to gentle, indistinct depressions. The map units reflect these various crater morphologies.

\section{NATURE OF SURFACE MATERIALS}

Before the successful Ranger missions, it was known that the moon was exceedingly rough on a scale comparable to the wavelength of light. (See for example, Minnaert, 1961.) Telescopic observations, however, indicated that the moon is relatively smooth over distances of several hundred meters, and early radar work indicated that this smoothness continues down to slope lengths of about 1 meter (Evans and Pettengill, 1963). The very rough microstructure was generally ascribed to either accumulations of a very fine grained particulate material in relatively open packing or to very porous foams or slags. Hapke (1964) reviewed photometric and polarimetric evidence, which favored the first of these alternatives. How deep such particulate material might be was not known.

Inferences about the nature of the lunar surface materials were drawn from three main aspects of the Ranger photographs: the size-frequency distribution of craters, the morphology of small craters, and the size and distribution of blocks on the surface. Another element of the topography seen at large scales that had a bearing on the interpretation of the surface materials was the series of closely spaced ridges and troughs known as patterned ground.

\section{CRATER STATISTICS}

One of the chief results of studies of the Ranger photographs was the extension of crater size-frequency curves some three orders of magnitude downward in crater diameter from the 1-km limiting resolution on the best telescopic photographs to near 1-meter resolution on the final Ranger frames. The number of craters of various sizes and their morphologies were critical to the problem of selecting sites for manned landings on the moon, and the Ranger photographs showed clearly that the moon was smooth enough over 1-meter slope lengths to permit such landings. Crater statistics also provided evidence bearing on the origin of the craters and the nature of the surface materials, but did not provide the final answers. Cumulative size-frequency diagrams of total craters for the three missions are given in figure 5. The following aspects of the curves are worthy of note. 1. Curves for the maria (Rangers VII, VIII) show a marked upward break in slope from slopes of approximately -1.7 to slopes of approximately -3 at crater diameters of between 5 and $1 \mathrm{~km}$. The very rapid increase in the number of craters in this interval is also measurable on high-resolution photographs taken at Lick Observatory, which became available at about the same time as the Ranger

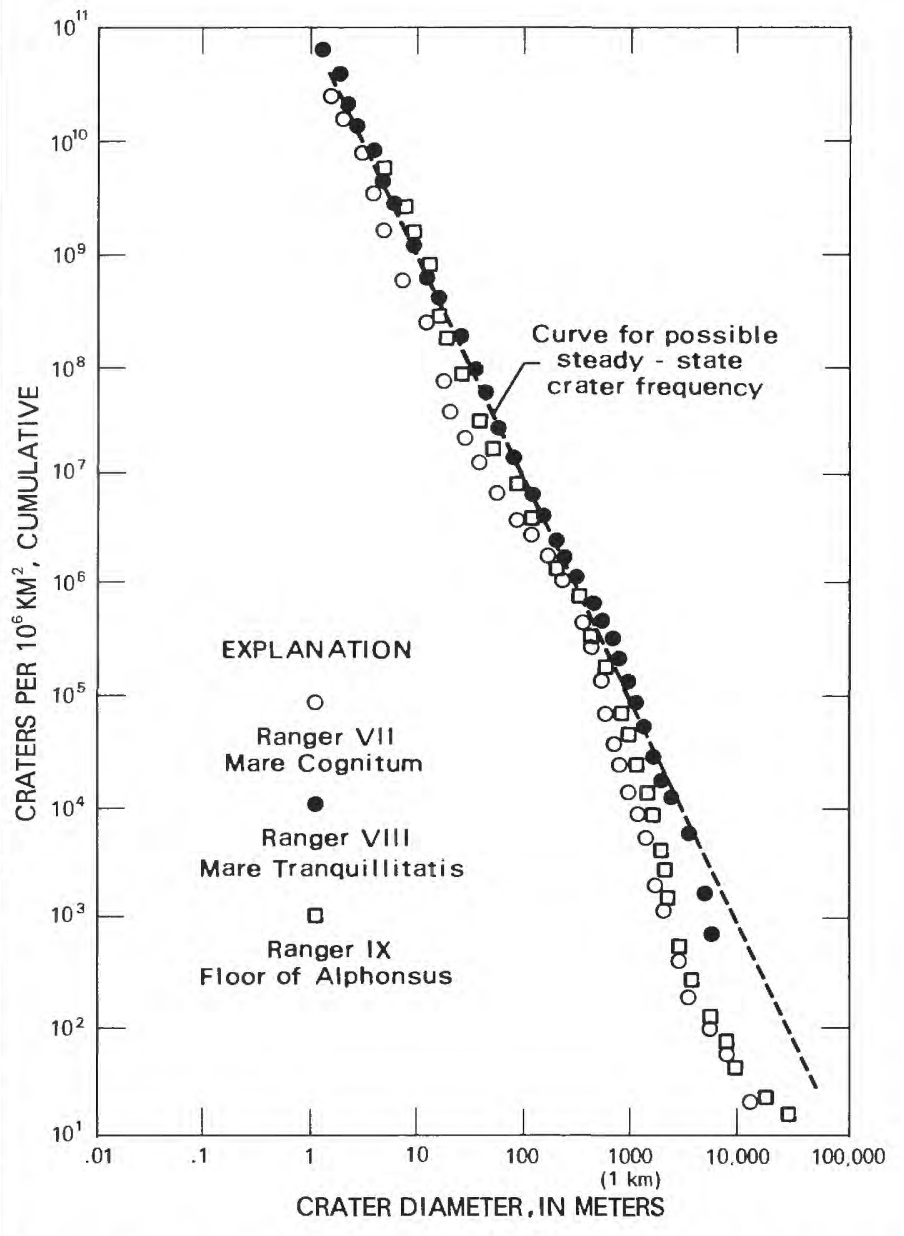

FIgURE 5.-Cumulative size-frequency distributions of craters photographed by Rangers VII, VIII, and IX. The area sampled is progressively smaller for smaller size craters. Craters larger than $2 \mathrm{~km}$ diameter on Mare Tranquillitatis counted from unpublished Lick Observatory photograph ECD-36. 
photographs. The existence of the upward break in slope means that extrapolations of crater counts in the maria from earlier earth-based observations (McGillem and Miller, 1962) give small-crater frequencies that are much too low.

2. Both curves for the maria undergo a second change in slope and become flatter at crater diameters of between 300 and $600 \mathrm{~m}$. The overall slope of the curves between diameters of 300 and $1 \mathrm{~m}$ is -2 . The resultant frequency of craters at $1 \mathrm{~m}$ is, of course, much lower than it would be if the higher slopes above $300 \mathrm{~m}$ diameter were maintained.

3. The crater frequency on the plains-forming material of the floor of Alphonsus is as much as an order of magnitude higher than on the maria at diameters of $1 \mathrm{~km}$; the size-frequency curve has a relatively steep slope of -3 for diameters above $2 \mathrm{~km}$ and a slope of -2 over the rest of its length, merging with the curve for the mare photographed by Ranger VIII at diameters of $10 \mathrm{~m}$.

In the interpretation of crater statistics derived from the Ranger photographs, it should be borne in mind that both the sun angle and the trace of the subspacecraft point on the lunar surface differed appreciably from one mission to another. The rather high sun angle in the Ranger VII mission probably results in failure to detect many subdued craters on Ranger VII photographs. Ranger VIII was maintained in the cruise mode without terminal maneuver so that successive photographs portray overlapping rather than nested areas; the crater statistics are thus a composite, with the statistics for small craters derived from a different area than the statistics for large craters.

The close agreement of the frequencies of small craters on three diverse surfaces photographed by the Ranger spacecraft (fig. 5) indicates that the most recent cratering history on all three has been similar. The high-resolution photographs from Lunar Orbiter give the same impression and have a rather monotonous similarity with a few exceptions. At larger crater diameters $(100 \mathrm{~m}-1 \mathrm{~km})$, there are much larger differences in the crater frequencies (fig. 5), a fact also evident on Orbiter" photographs. Proposed cratering histories of the moon must take into account these fundamental observations.

The question of the nature of the lunar surface material is tied to the question of the origin of craters. Shoemaker (1966) and Shoemaker and others (1966) proposed that most of the subdued craters were once sharp and have been degraded by subsequent micrometeorite impacts, seismic shaking, and downslope movement of material. In this model, parts of the crater size-frequency curves for large crater sizes refer to craters that have not been completely destroyed; they indicate the total number of craters larger than a given size that have ever been present on these surfaces. For the maria, these parts of the curves extend from crater diameters of from 300 to $600 \mathrm{~m}$ to the largest sizes and have slopes of approximately -3 for diameters as much as $5 \mathrm{~km}$ and shallower slopes for diameters above $5 \mathrm{~km}$; for the floor of Alphonsus, this part of the curve extends from diameters of $2 \mathrm{~km}$ to larger sizes and has a slope of approximately -3 . The parts of all three curves extending to the smallest craters (slope of -2 , fig. 5) would represent a steady-state population in which craters are destroyed at approximately the same rate at which they are formed. Thus, the number of craters smaller than $300-600 \mathrm{~m}$ in diameter would remain constant as the superposition of new craters destroyed preexisting ones. The close agreement of the frequencies of small craters on the three diverse surfaces sampled by the Rangers is consistent with this model. Because of the continual destruction of craters, most of the surface would be covered with a layer of fragmental debris several meters thick.

A complication to the steady-state model is the fact that the final frames of each Ranger mission show an increase in the proportion of sharp craters in the size range 10-50 $\mathrm{m}$ (Trask, 1967; Chapman, 1968). In a simple steady-state model of crater formation and destruction, the rate of crater formation is a simple power function of crater diameter, and the rate of crater destruction is proportional to the rate of crater formation (Moore, 1964). In such a model, the proportion of sharp craters should be the same at all crater diameters because the rates of crater formation and destruction would be balanced in the same way for all crater diameters below the limiting steady-state diameter. The fact that the proportion of sharp craters is not constant with crater diameter but varies in a regular way indicates that if the impact model is correct, the rate of crater formation or the rate of crater destruction or both may have varied with time and may have departed from a simple power dependence on crater diameter.

According to another interpretation, which explained the observed size-frequency distribution of craters equally well, the subdued craters are largely passive collapse depressions in lava flows (Kuiper and others, 1966). The subdued form would be a primary attribute, rather than the result of subsequent degradation. The sharper craters would be both primary and secondary impact craters, but they would not be numerous enough to cause the complete destruction of any preexisting crater $1 \mathrm{~m}$ in diameter or larger. Fragmental debris would be thin and possibly absent in places. 
A third interpretation ascribed the subdued appearance of most of the craters to a discrete event or series of events, such as covering by a series of ash-flow tuffs (O'Keefe, 1966). The sharper craters would postdate the covering event.

Crater statistics from Ranger photographs alone were not sufficient to resolve these differences in interpretation. Combined with evidence from the photometric and polarimetric properties of the moon, which indicated particulate material at the surface (Hapke, 1964), the photographs pointed very strongly, in my opinion, to meteorite impact having played a major role in forming the lunar surface material. Data from subsequent Orbiter, Surveyor, and Apollo missions have confirmed this picture. These data cannot be discussed in detail here, but they indicate that the surface material is fragmental to a depth of at least $5 \mathrm{~m}$, that material in the soil is strongly shocked, and that meteoritic material is present in significant amounts. Ages determined on returned samples suggest further that the rate of meteorite bombardment declined from a high early level connected with the formation of the moon, continued to decline or stayed at a relatively low level during the immediate postmare period, and rose to relatively high levels during more recent geologic time. The sharp craters $10-50 \mathrm{~m}$ in diameter so common on the final Ranger frames probably were formed during this recent increase in the flux.

\section{MORPHOLOGY OF SMALL CRATERS}

The smallest craters observed on the best Ranger photographs have diameters of from 1 to $2 \mathrm{~m}$; many in this size range have well-defined raised rims, and except for a few isolated examples, no blocks can be seen in the rim deposits. These characteristics are consistent with impact into a layer of noncohesive to weakly cohesive fragmental material, not with impact into a solid substrate such as a basalt flow (Shoemaker and others, 1966, p. 265; Gault and others, 1966). The Ranger photographs indicated that the grain size of this material must be below $25 \mathrm{~cm}$, the limiting resolution of the highest resolution frames. The presence of material with very fine grain size at the lunar surface had earlier been indicated by the photometric and polarimetric properties of the moon (Hapke, 1964, 1966). The morphology of the small craters seen on the Ranger photographs suggested that noncohesive to weakly cohesive material extended to a depth of at least several meters, a conclusion confirmed by the photographs returned by the soft-landed Surveyors a year or so later (Jaffe and others, 1969).

\section{BLOCKS ON THE LUNAR SURFACE}

In study of the Ranger data, considerable attention focused on the identification of positive-relief features, such as blocks on the plains-forming materials, because of the hazards they might present to lunar landings and because of the popular notion that the moon is craggy and rubbly. As noted previously, very few such features were found.

Central mounds were noted on the floors of several relatively fresh-appearing craters on the final frames of Rangers VII and VIII (Titley, 1971; Cannon and Rowan, 1971). Interpretations of these features ranged from suggestions that they were remnants of an impacting body to theories of sublimate deposits left by gases escaping from the lunar interior. Such central mound craters were found to be numerous in craters 50-200 $\mathrm{m}$ in diameter on Orbiter photographs and are apparently formed when an object passes through the uppermost surficial debris layer and just barely penetrates the lower solid substrate (Quaide and Oberbeck, 1968). These craters therefore give an indication of the thickness of the lunar regolith.

A field of very large blocks up to $10 \mathrm{~m}$ across was observed on the wall of a pan-shaped crater on one of the final Ranger VIII frames (fig. 4). Lunar Orbiter photographs show that many similar fields of blocks occur on the walls of shallow craters. They are evidently related to the processes by which craters are degraded and filled in and probably are coarser fragments of the lunar regolith left behind by the downslope movement of finer material (Cannon and Rowan, 1971).

Positive-relief features, scattered, small, and mostly indistinct, were noted on the final Ranger IX frames by Kuiper (1966) and interpreted as blocks with diameters just above the limiting resolution of the photographs $(25 \mathrm{~cm})$. Shoemaker and others $(1966$, p. 266$)$ interpreted these as lumps or clods of fragmental debris similar to lumps of ejecta deposited around missileimpact craters at White Sands Missile Range, New Mex., but Surveyor and Apollo photographs suggest that many may be discrete blocks partially embedded in the surficial material. On the assumption that the positive-relief features represented discrete blocks ejected from a nearby crater, Kuiper (1966) calculated the bearing capacity of the upper $30-50 \mathrm{~cm}$ of the lunar surface as approximately 2 newtons $/ \mathrm{cm}^{2}$. More refined calculations by Moore (1970) based on ejected blocks photographed by Lunar Orbiter yield strengths higher by about one order of magnitude; however, Kuiper's calculation was extremely significant in indicating that the surface material of the moon is fairly strong, rather than dangerously weak. 


\section{PATTERNED GROUND}

The final frames of all three Ranger missions revealed a series of very low ridges or mounds and intervening troughs dereloped on gentle slopes. This feature was referred to as "tree bark" texture by Kuiper" (1965); Shoemaker and others (1966) proposed that it be termed "lunar patterned ground." Individual ridges or mounds range from 5 to $30 \mathrm{~m}$ in width and from 15 to about $200 \mathrm{~m}$ in length. Relief on the patterned ground observed in the Ranger photographs is tens of centimeters. The texture is best shown on the photographs with lowest sun angle taken by Rangers VIII and IX. It does not reproduce well in halftone prints and is barely perceptible on the rim of the large pan-shaped crater in figure 4.

Kuiper (1965) suggested that the patterned ground was an original texture of lunar lava flows; because of the evidence for a surficial fragmental layer cited above, Shoemaker and others (1966) proposed that it developed in the regolith in response to slight movement along joints in the underlying bedrock. Shoemaker's explanation now appears to be more nearly correct. Lunar Orbiter photographs show that patterned ground with relief as much as several meters is widespread on almost all slopes in the lunar terrae where the surficial debris layer is thick, and the feature apparently is responsible for the "toasted marshmallow" appearance of the terrae noted by Kuiper (1966) and photographed by Ranger IX (fig. 2).

\section{SUMMARY}

Each of the three Ranger missions contributed to a greater understanding of the stratigraphy of major lunar geologic units that had been mapped prior to 1964. The manner in which the units can be divided in the various areas and at the various scales shown on the Ranger photographs is summarized in table 4 . The picture of the moon that emerged from the Ranger studies was one in which both impact and internal processes played major roles in sculpting surface features, with impact processes playing the greater part in the smallest features observed.

It is instructive to consider how the progression of knowledge outlined in table 4 might apply to the exploration of other planetary bodies with very tenuous atmospheres, such as Mercury or the Galilean satellites of Jupiter. The greatest information on regional geology is found on photographs with broad coverage and resolution extending from $1 \mathrm{~km}$ down to $0.5 \mathrm{~km}$ and is best displayed on small-scale maps (table 4). Important additional information having some bearing on possible theories of origin of specific features can be obtained by intermediate-scale mapping. The regional geologic context is not apparent at large scales; instead, data about the fine structure and state of aggregation of the outermost layer of the planet become available. Thus, photographs at the various scales supplement one another; high-resolution limited-area views lose much of their value without accompanying regional views of lower resolution, whereas the reverse is less true.

TABLE 4.-Summary of improved geologic knowledge of lunar units as shown on Ranger photographs at increasingly larger scales

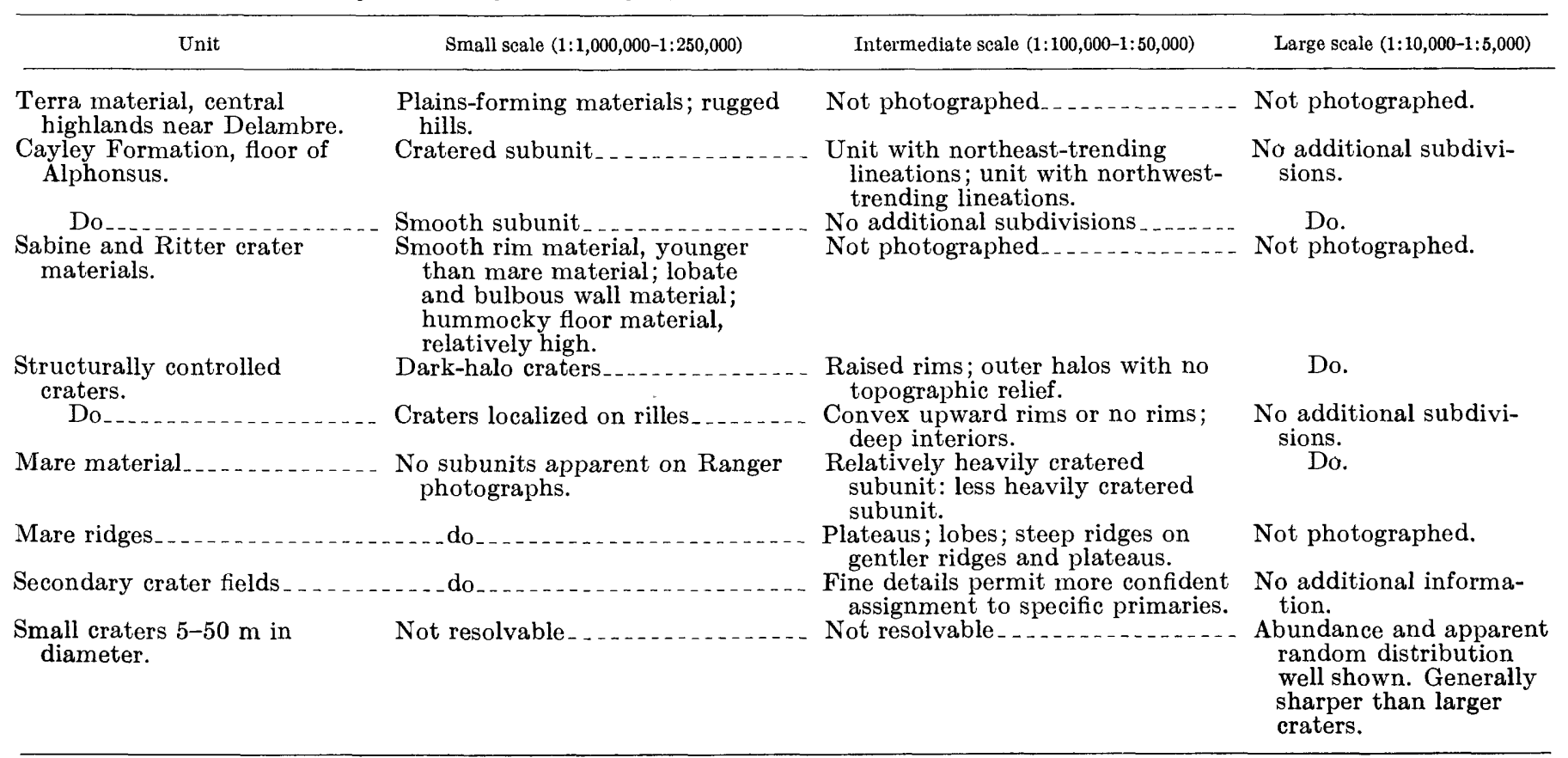


Combined with earlier telescopic views, the Ranger photographs provided a nearly complete picture for one side of the moon of the major types of features present, their distribution, and significant evidence bearing on their origin. Figure 6 shows in graphical form the type of information conveyed with varying field of view and resolution in the photographs. For comparison, the coverage and resolution expected to be achieved on the 1974 Mariner mission to Mercury are also plotted. Flybys of the planets planned for the immediate future, such as the 1974 mission to Mercury, will have resolutions limited to about $100 \mathrm{~m}$ at best because of the high velocities of the spacecraft with respect to the planets.

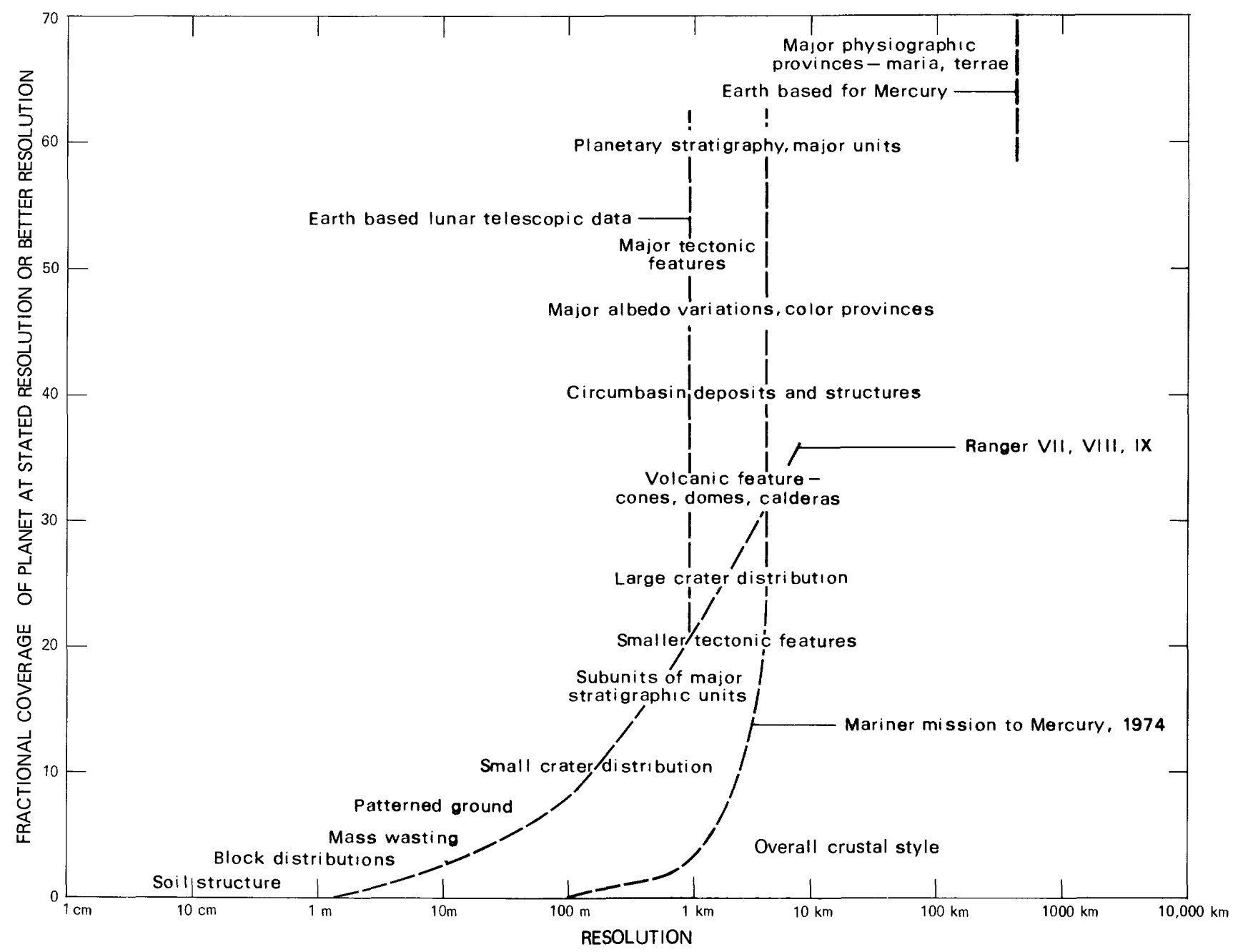

Frgure 6.-Hierarchy of geologic features on a typical planetary surface plotted in terms of resolution and fractional coverage of planet achieved by a photographic system. Rangers VII, VIII, and IX compared with anticipated coverage of a planned mission to Mercury in 1974. Limits of earth-based studies also shown. (After Masursky and others, 1970.) 


\section{REFERENCES CITED}

Cannon, P. J., and Rowan, L. C., 1971, Geologic map of the Sabine EB region of the Moon: U.S. Geol. Survey Misc. Geol. Inv. Map I-679. scale $1: 5,000$.

Carr, M. H., 1964, Impact induced volcanism, in Astrogeol. Studies Ann. Prog. Rept., July 1, 1963-July 1, 1964, pt. A : U.S. Geol. Survey open-file report, p. 52-66.

1969, Geologic map of the Alphonsus region of the Moon: U.S. Geol. Survey Misc. Geol. Inv. map I-599, scale $1: 250,000$.

Chapman, C. R., 1968, Interpretation of the diameter-frequency relation for lunar craters photographed by Rangers VII, VIII, and IX : Icarus, v. 8, no. 1, p. 6-10.

Evans, J. V., and Pettengill, G. H., 1963, The scattering behavior of the moon at wavelengths of $3.6,68$, an 784 centimeters : Jour. Geoplrys. Research, v. 68, no. 2, p. 423-447.

Gault, D. E., Quaide, W. L., and Oberbeck, V. R., 1966, Interpreting Ranger photographs from impact cratering studies, in Hess, W. N., Menzel, D. H., and O'Keefe, J. A., eds., The nature of the lunar surface: Baltimore, Johns Hopkins Press, p. 125-140.

Hapke, B. W., 1964. Photometric and other laboratory studies relating to the lunar surface, in Salisbury, J. W., and Glaser, P. E., eds., The lunar surface layer: New York, Academic Press, 532 p.

1966, Optical properties of the moon's surface, in Hess, W. N., Menzel, D. H., and O'Keefe, J. A., eds., The nature of the lunar surface: Baltimore, Johns Hopkins Press, p. 141154.

Hartmann, W. K., 1968, Lunar crater counts VI: The young craters Tycho, Aristarchus and Copernicus: Univ. Arizona Lunar and Planetary Lab. Commun., v. 7 , pt. 3, no. 119, p. 145-156.

Heacock, R. L., Kuiper, G. P. Shoemaker, E. M., Urey, H. C., and Whitaker, E. A., 1965, Ranger VII ; Part 2, Experimenters' analyses and interpretations: Calif. Inst. Technology, Jet Propulsion Lab., Tech. Rept. 32-700, 154 p.

- 1966, Ranger VIII and IX; Part 2, Experimenters' analyses and interpretations: Calif. Inst. Technology, Jet Propulsion Lab., Tech. Rept. 32-800, 382 p.

Hess, IV. N., Menzel, D. H., and O'Keefe, J. A., eds., 1966, The nature of the lunar surface: Baltimore, Johns Hopkins Press, $320 \mathrm{p}$.

Howard, K. A., and Masursky, Harold, 1968, Geologic map of the Ptolemaeus quadrangle of the moon: U.S. Geol. Survey Misc. Geol. Inv. Map I-566, scale 1: 1,000,000.

Jaffe, L. D., Alley, C. O., Batterson, S. A., Christensen, E. M., Dwornik, S. E., Gault, D. E., Lucas, J. W., Muhleman, D. O., Norton, R. H., Shoemaker, E. M., Steinbacher, R. H., Sutton, G. H., and Turkevich, A. L., 1969, Principal science results from the Surveyor project, in Surveyor project final report; Part 2, Science results : Calif. Inst. Technology, Jet Propulsion Lab. Tech. Rept. 32-1265, p. 15-20.

Kozyrev, N. A., 1962, Physical observations of the lunar surface, in Kopal Zdenék, ed., Physics and astronomy of the moon : London, Academic Press, p. 361-383.

Kuiper, G. P., 1965, Intepretation of Ranger VII records, in Ranger VII ; Part 2, Experimenters' analyses and interpretations: Calif. Inst. Technology, Jet Propulsion Lab. Tech. Rept. 32-700, p. 9-74.

1966, The surface structure of the moon, in Hess, W. N., Menzel, D. H., and O'Keefe, Jr. A., eds., The nature of the lunar surface: Baltimore, Johns Hopkins Press, p. 99-105.
Kuiper, G. P., Strom, R. G., and LePoole, R. S., 1966, Interpretation of the Ranger records, in Ranger VIII and IX ; Part 2, Experimenters' analyses and interpretations: Calif. Inst. Technology, Jet Propulsion Lab. Tech. Rept. 32-800, p. 35248.

Masursky, H., Batson, R., Borgeson, W., Carr, M., McCauley, J., Milton, D., Wildey, R., Wilhelms, D., Murray, B., Horowitz, N., Leighton R., Sharp, R., Thompson, W., Briggs, G., Chandeysson, P., Shipley, E., Sagan, C., Pollack, J., Lederberg, J., Levinthal, E., Hartmann, W., McCord, T., Smith, B., Davies, M., de Vaucouleurs, G., and Leovy, C., 1970, Television experiment for Mariner Mars 1971 : Icarus, v. 12, no. 1, p. 10-45.

McCauley, J. F., 1968, Geologic results of lunar precursor probes : Am. Inst. Aeronautics and Astronauties Jour., v. 6, no. 1, p. 1991-1996.

1969, Geologic map of the Alphonsus GA region of the moon: U.S. Geol. Survey Misc. Geol. Inv. Map I-586, scale $1: 50,000$.

McGillem, C. D., and Miller, B. D., 1962, Lunar surface roughness from crater statisties: Jour. Geophys. Research, v. 67, no. 12 , p. $4787-4794$.

Milton, D. J., 1968, Geologic map of the Theophilus quadrangle of the moon: U.S. Geol. Survey Misc. Geol. Inv. Map I-546, scale $1: 1,000,000$.

Minnaert, M. G. J., 1961, Photometry of the moon, Chapter 6 in Kuiper, G. P., and Middlehurst, B. M., eds., Planets and satellites, volume 3 of The solar system: Chicago, Univ. Chicago Press, p. 213-248.

Moore, H. J., 1964, Density of small craters on the lunar surface, in Astrogeol. Studies Ann. Prog. Rept., August 1962-July 1963, pt. D : U.S. Geol. Survey open-file report, p. 34-51.

1970, Estimates of the mechanical properties of lunar surface using tracks and secondary impact eraters produced by blocks and boulders: U.S. Geol. Survey open-file report, $65 \mathrm{p}$.

Morris, E. C., and Wilhelms, D. E., 1967, Geologic map of the Julius Caesar quadrangle of the Moon: U.S. Geol. Survey Misc. Geol. Inv. Map I-510, seale 1: 1,000,000.

Mutch, T. A., 1970, Geology of the moon : Princeton, N. J., Princeton Univ. Press, 324 p.

National Aeronautics and Space Administration, 1964, Camera "A" Series, Ranger VII photographs of the moon: U.S. Natl. Aeronautics and Space Adm. Spec. Pub. 61, 17 p., 199 pls.

1965a, Camera "B" Series, Ranger VII photographs of the moon: U.S. Natl. Aeronautics and Space Adm. Spec. Pub. 62, 17 p., 199 pls.

-1965b, Camera "P" Series, Ranger VII photographs of the moon: U.S. Natl. Aeronauties and Space Adm. Spec. Pub. 63,27 p., 200 pls.

-1966a, Cameras "A", "B", and "P" Series, Ranger VIII photographs of the moon: U.S. Natl. Aeronautics and Space Adm. Spec. Pub. 111, 17 p., 170 pls.

1966b, Cameras "A", "B", and "P" Series, Ranger IX photographs of the moon: U.S. Natl. Aeronautics and Space Adm. Spec. Pub. 112, 17 p., 170 pls.

O'Keefe, J. A., 1966, Lunar ash fiows, in Hess, W. N., Menzel, D. H., and O'Keefe, J. A., eds., The nature of the lunar surface : Baltimore, Johns Hopkins Press, p. 259-266.

Quaide, W. L., and Oberbeck, V. R., 1968, Thickness determinations of the lunar surface layer from lunar impact eraters: Jour. Geophys. Research, v. 73, no. 16, p. 5247. 
Shoemaker, E. M., 1966, Preliminary analysis of the fine structure of the lunar surface in Mare Cognitum, in Hess, W. N., Menzel, D. H., and O'Keefe, J. A., eds., The nature of the lunar surface: Baltimore, Johns Hopkins Press, p. 23-77.

Shoemaker, E. M., Alderman, J. D., Borgeson, W. T., Carr, M. H., Lugn, R. V., McCauley, J. F., Milton, D. J., Moore, H. J., Schmitt, H. H., Trask, N. J., Wilhelms, D. E., and Wu, S. C. C., 1966, Progress in the analysis of the fine structure and geology of the lunar surface from the Ranger VIII and IX photographs, in Ranger VIII and IX; Part 2, Experimenters' analyses and interpretations: Calif. Inst. Technology, Jet Propulsion Tech. Rept. 32-800, p. 249-338.

Shoemaker, E. M., and Hackman, R. J., 1962, Stratigraphic basis for a lunar time scale, in Kopal, Zdenék, and Mikhailov, Z. K., eds., The moon-Internat. Astron. Union Symposium 14, Leningrad, 1960 : London, Academic Press, p. 289-300.

Titley, S. R., 1968, Preliminary geologic map of the Bonpland $\mathbf{H}$ region of the moon: U.S. Geol. Survey open-file report, scale $1: 100,000$.

1971, Geologic map of the Bonpland PQC region of the moon: U.S. Geol. Survey Misc. Geol. Inv. Map I-678.
Trask, N. J., 1967, Distribution of lunar craters according to morphology from Ranger VIII and IX photographs: Icarus, v. 6 , no. 2 , p. 270-276.

1969, Geologic map of the Sabine DM region of the moon : U.S. Geol. Survey Misc. Geol. Inv. Map I-594, scale 1 : 50,000.

U.S. Geological Survey, 1971, Geologic map of the Bonpland $\mathbf{H}$ region of the moon: U.S. Geol. Survey Misc. Geol. Inv. Map I-693, scale $1: 100,000$.

Urey, H. C., 1965, Observations on the Ranger VII pictures, in Ranger VII ; Part 2, Experimenters' analyses and interpretations: California Inst. Technology, Jet Propulsion Lab. Tech. Rept. 32-700, p. 135-148.

Wilhelms, D. E., 1970, Summary of lunar stratigraphy-telescopic observations: U.S. Geol. Survey Prof. Paper 599-F, $47 \mathrm{p}$.

Wilshire, H. G., 1967, Preliminary photogeologic map of the Sabine region of the moon, in Astrogeol. Studies Ann. Prog. Rept. July 1, 1965-July 1, 1966 : U.S. Geol. Survey open-file report, scale $1: 250,000$, map supp. 


\section{Contributions to}

\section{Astrogeology,}

1967-71

GEOLOGICAL SURVEY PROFESIONAL PAPER 599

This volume was published

as separate chapters $A-J$

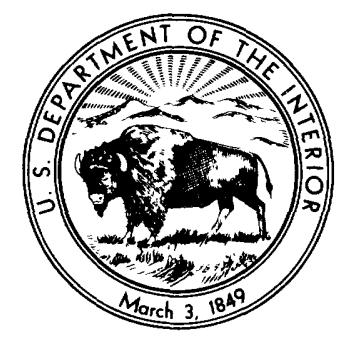



, 


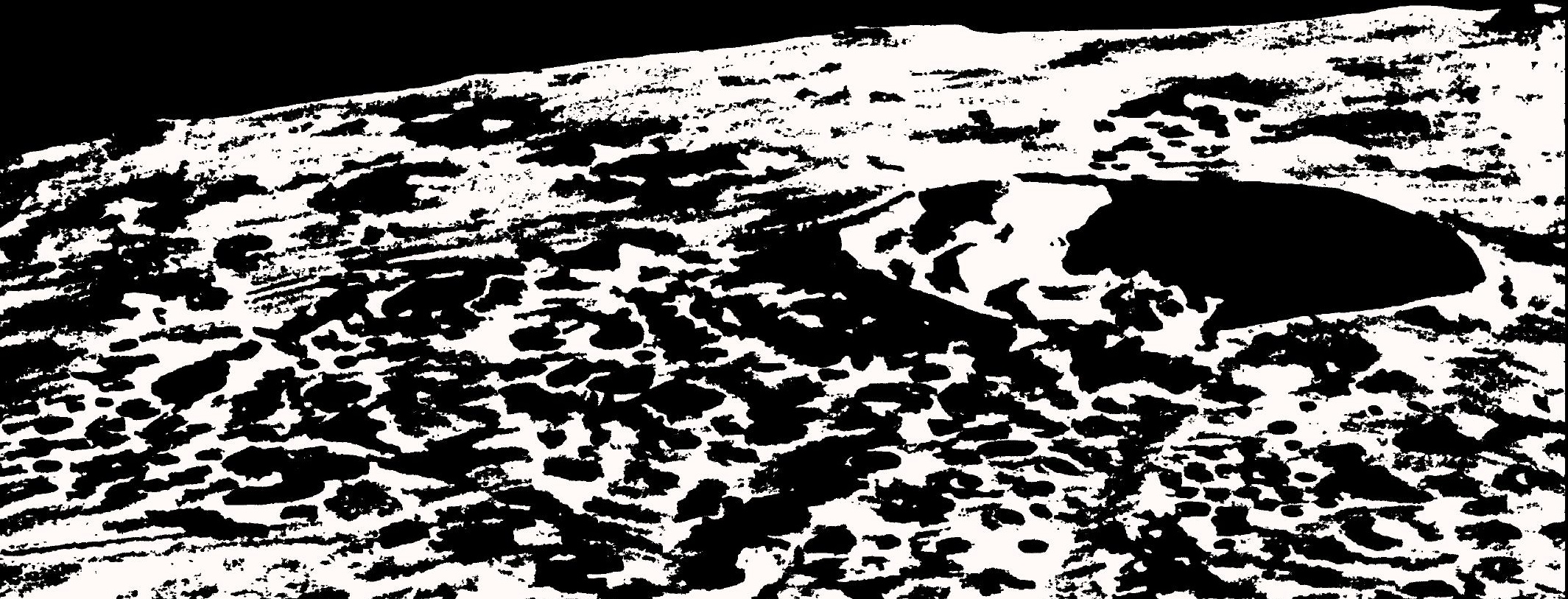

